\title{
Transformations of Entrepreneurial Competence in Activities
}

\author{
Genute Gedviliene, Professor, PhD \\ Virginija Bortkeviciene, PhD candidate
}

Department of Education Science, Vytautas Magnus University, Lithuania

doi: 10.19044/esj.2016.v12n34p135 URL:http://dx.doi.org/10.19044/esj.2016.v12n34p135

\begin{abstract}
Scientific literature revealed entrepreneurship as quite a complex and multifaceted concept which combines different scientific disciplines and may be expressed through them. Entrepreneurship is a topic of educational and economic interest at the present time and is described as a creative and innovative response to environments, which can be and can occur in different social environment: in business, in education, social work, and industry etc. The question is how to measure what determines the entrepreneurship in activities? How entrepreneurial competence is experienced and how entrepreneurial knowledge transformations are going into activities and how entrepreneurial knowledge is acquired before the onset of the action? The purpose of this paper is to identify how entrepreneurial competence is experienced and what determines manifestation of entrepreneurial competence in activities. Research methodology. A phenomenographic research approach was adopted and semi-structural interviews with entrepreneurs identified as the most appropriate data collection tool. Findings. The research data revealed the ways that entrepreneurial competence is experienced in activities and the ways how this competence transforms into activities: through theoretical knowledge or through practical knowing. Implications. The identified categories of descriptions in this research could support a learning process: what kind of learning forms we need seeking a better understanding about entrepreneurial competence and a better use of entrepreneurial competence while this competence transforms into activities.
\end{abstract}

Keywords: Entrepreneurial competence, phenomenography, theoretical knowledge, practical knowing 


\section{Introduction}

Discussions about entrepreneurship and education is becoming stronger in these days. Acquisition of entrepreneurial knowledge is an important learning process, which takes place in both: theory and practice. According to Higgins and Elliot (2011, 345), learning and opportunities to learn are at the center of entrepreneurial practice. The European Union (2002) also prioritized entrepreneurship and the development of entrepreneurial competence as a key factor. Further the EU Employment guidelines point out entrepreneurship as a priority in the education system. The European Commission Green paper Entrepreneurship in Europe (2003), discusses that society needs to encourage entrepreneurship by fostering entrepreneurship skills and abilities as well as entrepreneurial knowledge and practice. In this context it is important to answer a question „How entrepreneurial competence is experienced and how entrepreneurial competence transforms into activities and what is more important theoretical knowledge or practical knowing?

Entrepreneurial learning theories. In the field of Entrepreneurial learning there are many different learning theories. These theories combine experiential, action and transformation learning theory. As Lindeman (1926) points out that ,the resource of highest value in adult education is the learner's experience“. So in this context action and the experience are the most important factors while learning entrepreneurship and developing entrepreneurial competence. Experiential learning is based on the past experiences. According to Kolb (1984, p.38) learning ,is the process whereby knowledge is created through the transformation of experience“. Action learning as Higgins and Elliot state (2011), is situated in the process of on-going practice, rooted in a context of social interaction (where learning also takes place) and acquired through participation. Action learning „is not solely concern with learning by doing or learning by participation, but with leading the learner towards the acquisition of new knowledge and the conceptualization of experience" (Gibb, 2008, p.223). Transformative learning theory according to Mezirow $(1996,162)$ is a theory where learning is understood as the process of using a prior interpretation to construct a new or revised interpretation of the meaning of one's experience in order to guide future action“.

Methodology. In this paper the qualitative research methodology was chosen and the phenomenography approach adopted. The methodology of the phenomenography is based on Marton and his works in the late 1970s (Marton 1978) and early 1980s (Marton 1981, Marton 1986). When Marton first introduced phenomenography, he described it as being content-oriented and aiming at forming an experiential description of ,qualitatively different ways in which people perceive and understand their reality $(1981,177)$. 
Marton (1986, 31) defined the approach as ,a research method adapted for mapping the qualitative different ways in which people experience, conceptualize, perceive and understand various aspects of, and phenomena in, the world around them“.

Sample and data collection. In this research purposeful sampling strategy were adopted (Patton 2002, 243). Participants in this research were selected according to their appropriateness to the purpose of this research that is, that they have experience in the phenomena that have been explored. In this research semi-structured interviews were used as the main tool for data collection. In phenomenographic research the researcher does not need to try to describe what reality is (first order perspective), but the researcher needs to describe how it is experienced and described by the people who experience it (second order perspective). All interviews in this research were collected from March, 2015 till March, 2016. Each interview lasted between forty five minutes and ninety minutes. All interviews were conducted, tape recorded and transcribed by the researcher. It was conducted twenty four interviews in total.

Data analyses. The main phenomenon in this research was entrepreneurial competence and the main purpose of this research was to identify and to describe how entrepreneurial competence is experienced and what determines manifestation of entrepreneurial competence in activities. The main result of this research was to reveal the Categories of Description in an outcome space. So in this research it was important to describe how entrepreneurial competence is experienced by the research participants using the second order perspective. In this research the author preferred the five stage procedure to data analyses by Marton, Ashworth and Lucas. According Marton (1986) and Ashworth and Lucas (2000), the following stages are involved: (1) Becoming familiar with the data (2) Identifying the relevant parts of the data (3) Looking for themes - "pools of meaning” (4) Grouping quotes according the meaning (5) Development of categories of description.

Ethical considerations. The research was influenced by ethical principles at all the stages of this research. Ethical principles were addressed as follows: All participants were participating in this research anonymously Participants were informed about the time and they were assured that their identity would remain anonymous, but the quotes they made could be used in the research giving them anonymous code. Results of the research. The results of the research in this paper are presented as a set of Categories of description in the outcome space, indicating a qualitatively different ways of experiencing entrepreneurial competence. To respond the research question of this paper "How entrepreneurial competence is experienced and how entrepreneurial knowledge transformations are going into activities" there were found seven Categories of description (See Table 1): (1) An 
autonomous freedom of action, (2) Self-identification (3) Learning in activities (4) A pragmatic approach to learning (5) Continuous growth and development (6) Integration of theory and practice (7) An entrepreneur picture formation. The author of the research named Categories of description according to the key features. Categories of description represent relationship between theory and the empirical results.

Table 1 Categories of description

\begin{tabular}{|c|c|c|}
\hline $\begin{array}{c}\text { Categories of } \\
\text { description }\end{array}$ & $\begin{array}{c}\text { Sub-categories } \\
\text { image formation }\end{array}$ & $\begin{array}{c}\text { Vocation of an entrepreneur, Entrepreneurship development, } \\
\text { Business roles of entrepreneur, The environmental impact on } \\
\text { affecting entrepreneur formation }\end{array}$ \\
\hline & Self-identification & $\begin{array}{c}\text { Self-identification, Identification of character and personal } \\
\text { features for business, Identification of favourite activities, } \\
\text { Recognition of limitations of personal knowing, Self-evaluation }\end{array}$ \\
\hline & $\begin{array}{c}\text { An autonomous } \\
\text { freedom of action } \\
\text { Pragmatic approach to } \\
\text { learning }\end{array}$ & $\begin{array}{c}\text { Learning pragmatism, Activity pragmatism, Practical } \\
\text { application of knowledge, Intellectual decisions }\end{array}$ \\
\hline $\begin{array}{c}\text { Learning in activities } \\
\text { anding }\end{array}$ & $\begin{array}{c}\text { Learning in activities, Experiential learning, Collaborative } \\
\text { learning and learning in the interaction with the others }\end{array}$ \\
\hline $\begin{array}{c}\text { Integration of theory } \\
\text { and practise }\end{array}$ & $\begin{array}{c}\text { Merging theory and practise, Choice of learning methods, } \\
\text { Necessity of formal studies, Practical knowledge advantage }\end{array}$ \\
\hline $\begin{array}{c}\text { Continuous growth } \\
\text { and development }\end{array}$ & $\begin{array}{c}\text { Continuous growth and development, Independent learning, } \\
\text { Learning to learn }\end{array}$ \\
\hline
\end{tabular}

\section{Categories of Description}

Self-Identification. In this category of description research participants recognize themselves as personalities. It helps them to find the right ways for self-realization. The data showed that informants were experiencing entrepreneurial competence in different activities and environments. In this category of description informants are aware of their entrepreneurial competence in terms of making meaning what kind of personal features could contribute to their entrepreneurial competence. This Category includes five sub-categories that is: self-identification, identification of character and personal features for business, identification of favorite activities, recognition of limitations of personal knowing and selfevaluation. See quote bellow:

„This is a trust of your idea when you see the potential in that idea that you boldly submit this, you creatively give this idea to the others. I do not know, at least for me creativity, courage has helped me, when you're not afraid to experiment, <..> > So I really wasn't scared to try something new and somehow to impress my clients and market IN8_V“.

An autonomous freedom of action. This category focuses of what is happening with adults, when they feel that they have entrepreneurial 
competence. The research results showed that they want to be independent, autonomous:

"One thing and probably the most important thing, it is to be independent. The most important thing is that you do not fear, that you will be sacked, you do not fear that someone will tell you what to do and how to behave, it was the first moment. Second, it was independence. When you are independent, you can plan your activities on your own. And the third thing, in fact I wanted to do something for myself, so that I could be proud of. This goal was more egoistic as to say IN3_V”.

Entrepreneurs want to take responsibility for their decisions and to feel self-confident:

"You can start, of course, not investing too much in education, but I did not want to, I wanted to be self-confident and to know what I'm doing and to do my job perfectly, but the idea still ...it was running from the school times, but perhaps from the very beginning I did not really trusted on my own <...> I had more to be self-confident IN12_V”.

This Category of description includes five sub-categories: target pursuit (See quote bellow), autonomy pursuit, self-confidence pursuit and continuous growth of self-confidence, value base in activities, responsibility.

"Again, you need to watch in a way, that you could go further, to set new goals, you should want to achieve the purpose and you should work that you could to achieve that goal. Then you're already back to businesses and so on ... Such a process ... ... Such are the steps ... You go up, and again you need to go up again, and you might need and you should be determined to achieve your goals IN3_V“

Category "Learning in activities”. When speaking about experiencing entrepreneurial competence it is important that categories of description are connected with learning. One of the main categories concentrating to learning process is learning in activities. Learning in activities category includes: learning in activities, experiential learning, and collaborative learning i.e. learning in the interaction with the others:

„We also have a circle of colleagues with whom we are communicating quite often. We often call, often communicate using e-mails. Well, if we are going to a workshop, we share. You can often call to anyone and say, look, something does not work, perhaps you have tried this and you could share IN11_V“.

Learning in activities introduces a variety of manifestations of entrepreneurial competence and the ways of learning: learning in activities, which combines workplace learning; experiential learning or learning by doing; learning from experts and authorities:

"Undoubtedly these studies at xxx university helped a lot, because there I met professors, who most of them for many years had their own 
business and who talked a lot of from practical side, not only theoretically and which adapts their knowledge's practically every day <...> IN5_V“.

The research participant's points out that mostly knowledge and skills were learned and acquired through practice, practical situations, collaboration and in workplace.

"Well, all knowledge is from my work experience <.. > IN4_V".

In the Category Integration of theory and Practice the main focus is that entrepreneurs are aware of their learning in terms of combining theory with practice. This main category is divided into four sub-categories: merging theory and practice, choice of learning methods, necessity of formal studies, practical knowledge advantage. This category describes situations where learners understand theory and check theoretical knowledge's through their work and practical situations. So the participants of the research pointed out the importance of the coherence of theoretical and practical knowledge in the learning process. This understanding is illustrated in the quote bellow:

„When there is theory and you engage in practice it is much easier, much easier. Another thing if there is only theory, but there is no practice... again. Ideally, when you have certain theoretical background and begin to work in that field, but on the other hand theory and practice should be related. IN10_V“.

Continuous growth and development. In this Category of description the study participants are aware of their continuous learning in terms of enhancing their capabilities and gaining new knowledge. This category of description includes these sub-categories: continuous growth, independent learning, learning to learn. The data illustrates (see the quote bellow) that study participants are often face by the learning needs and they are ready to learn when they are facing a need for a certain knowledge or skills This category focuses on and analysis of adults learning needs:

„I am planning to live for a long time and I am planning to study further, because I see that every day, when I face with a situation I can see my own gaps, and then I am going to trainings, to fill the gaps: if necessary accounting, if necessary - the languages, if necessary- knowledge of business, and where I can see a gap I am keen immediately to develop myself through courses, trainings, and sometimes there is a lack of day time ... really ... and still I need to read books...IN5_V.“

Category describes the personal development and continuous learning process, independent learning:

"The knowledge for profession ... we will have to improve them throughout all life, because things are changing, everything is moving and it does not matter, whether you want or not to improve, but you have to improve <...> IN3_V“. 
A pragmatic approach to learning. This category is associated with the receipt of benefits, which is quite related to the very nature of entrepreneurial competence. Entrepreneurship is often associated with certain benefits from the profit or the pursuit of added value. Adults seek to get some benefits and adaptability in the learning process as well.

„And there were quite a few cases where I had to use my theoretical knowledge. And in this company everything is done by my own. IN11_V“.

A pragmatic approach is encouraging study participants and to seek and want to adapt and use what they have gained in the learning process as soon as possible. This suggests that learning activities must meet the needs of the adults in business.

„The university gave me theoretical basis, but it did not give me the practical applications. I have not seen the practical applications, we have not learned this. We gwere given a lot of theoretical information, and we know that in theory this should be so, but in practice.... it needs more explanations ...it works quite differently IN3_V“.

This Category of description includes sub-categories as learning pragmatism, activity pragmatism, practical application of knowledge, intellectual decisions.

"Mostly I prefer some kind of practical methods, because information through practical methods is better absorbed, rather than the theoretical. $<\ldots>$ practical exercises, they will immediately give you the knowledge and competencies IN4_V“.

An entrepreneur image formation. In this category entrepreneurial competence is experienced through cognition of an entrepreneurial process. This category links to an entrepreneur figure describing in sub-categories the main process as: Vocation of an entrepreneur, Entrepreneurship development, business roles, the environmental impact on affecting business. This category forms the understanding of the entrepreneur and its characteristic features;

"First of all, this is my today's opinion, that business people, they have to be born with a business flair <...>. And that, what I'm doing now, I have been doing it already since childhood IN5_V“.

This is about what forms the entrepreneurship and entrepreneurial competence. The research participants agree that it is both: completed studies and the development of entrepreneurship:

„I would say that I still need to develop entrepreneurship, I still need to develop this feature, but it is the same as ... well as any human feature that has to be developed and nurtured over a lifetime. Because you can't say that yes I simply reached a level and I'm really a business man < ... IN3_V”. 
Finally concluding the research results Figure 1 summarizes qualitatively different ways of experiencing entrepreneurial competence. (See. Fig.1)

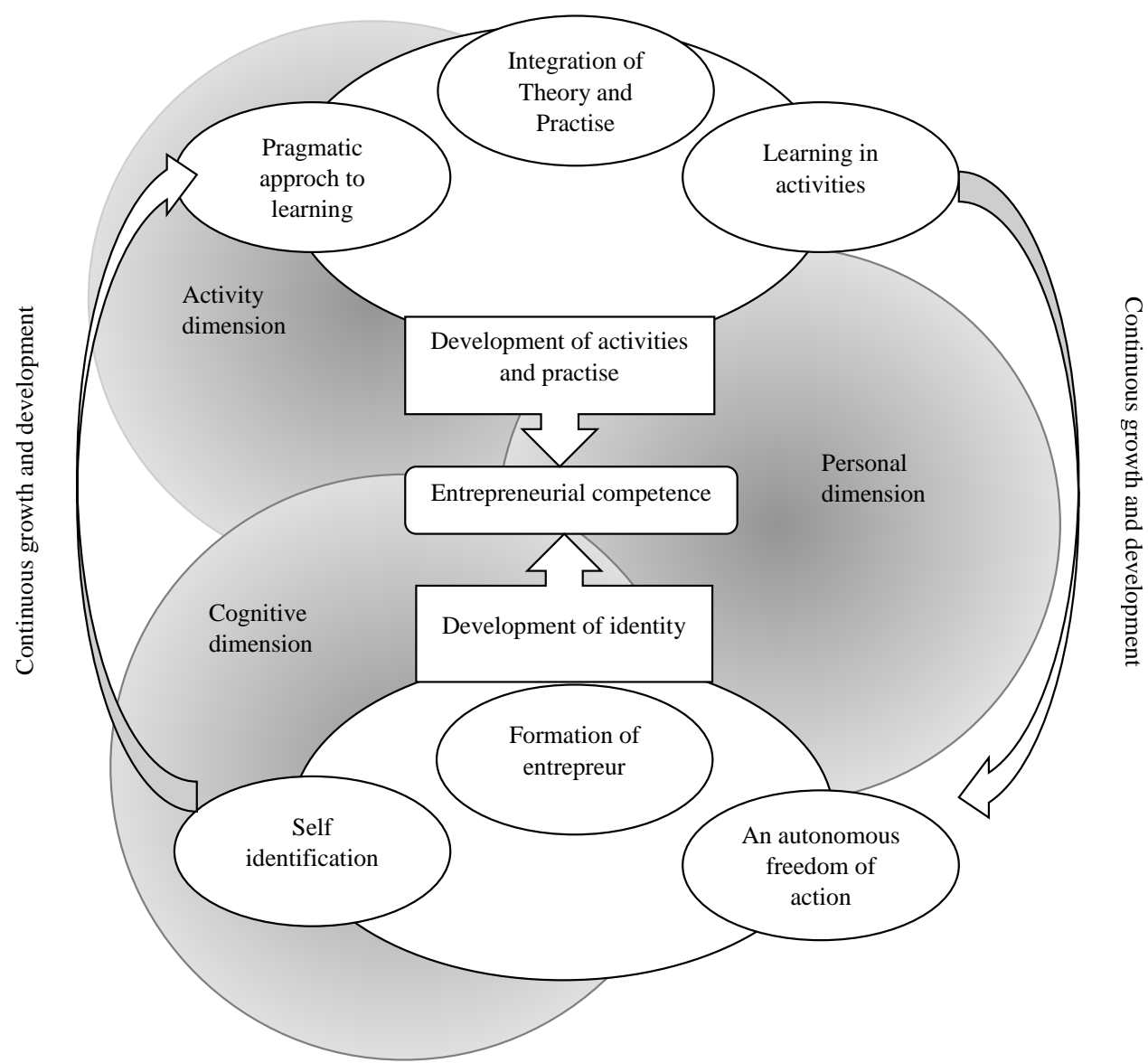

Figure 1. The outcome space of experiencing Entrepreneurial competence

\section{Discussion: findings, conclusions}

The overall research showed that entrepreneurial competence learning could be experienced in different ways and in different learning environments. The main finding that emerged from this research is that the research participants experienced entrepreneurial competence in qualitatively different ways described through the Categories of description. In the research a variety of different learning theories were found as the theories that contribute to the entrepreneurial competence development. The experiential theory (Kolb, 1984), action learning theory (Revans, 2011), transformational learning theory (Mezirow, 1996) contributed to the entrepreneurial learning process. Also results showed, that while study 
participants experience entrepreneurial competence and while the entrepreneurial competence manifestation is going into activities, the research participants face integration of different types of knowledge (theoretical, practical, self-regulated). While analyzing, how entrepreneurial competence is experienced, the results showed that all this process is about learning to discover, evaluate and act on opportunities in unplanned events unexpectedly occurring real-life situation (Jones, 2011). The data showed that research participants, while they are experiencing entrepreneurial competence they are responsible for their own learning and they are expected to be able to regulate their learning in a experiential, collaborative, transformational learning environments. So the process of entrepreneurial competence transformation into activities should provide freedom, creativity, to enable to be responsible for their own decisions in learning process (Jones, 2011). The results showed that different learning environments help us to recognize entrepreneurial competence manifestation in activities. Entrepreneurial competence manifestations into activities could be recognized in directed (formal learning environment) and incidental (informal learning) learning activities. As Gregoire et al. stated (2011), entrepreneurial competence experience through learning and the other environments could be seen as a process. In his works, Gregoire et al. (2011) advices to treat learning in entrepreneurship as as a process. So the question could be what should happen in education in order to deliver good preparation of entrepreneurs and to develop their entrepreneurial competence as well as independence, self-employment and entrepreneurship? Daloz $(1986,16)$ stated, that education is a transformational journey, that should promote development and transformational learning, which seeks to transform adult learners' perspectives through action learning. According Mezirow (2000, 3-4) in adulthood we may more clearly understand our experience when we know under what conditions an expressed idea is true or justified. So the research results proved that adult learners in business environment and in practise gain their knowledge using their previous experience. Learning activities that occur in informant's daily life, work were related to the environment, experiential learning process and helped informants to experience entrepreneurial competence.

\section{References:}

1. Ashworth, P., Lucas, U. (2000). Achieving empathy and engagement: a practical approach to the design, conduct and reporting of phenomenographic research. Studies in Higher Education, 25(3), 295-308. 
2. Gibb, A. (2008). Entrepreneurship and enterprise education in schools and colleges: Insights from UK practice. International Journal of Entrepreneurship Education 6, 101-144.

3. Gregoire, D. A., Corbett, A. C., \& McMullen, J. S. (2011) the cognitive perspective in entrepreneurship: agenda for future research. Journal of Management studies, 48 (6).

4. Higgins, D., \& Elliot C. (2011). Learning to make sense: What works in Entrepreneurial education? Journal of European Industrial Training, 35(4) 345-367.

5. Jones, C. (2011). Teaching Entrepreneurship to Undergraduates. Cheltenham, UK: Edward Elgar Publishing Limited.

6. European Commission 2002. Final Report of the Expert Group "Best Procedure". Project on Education and Training for Entrepreneurship. November 2002.

7. Kolb, D. A. (1984). Experiential learning: experience as the source of learning and development. Englewood Cliffs, NJ: Prentice Hall.

8. Knowles, M. (1984). The Adult Learner. Neglected Species $\left(3^{\text {rd }}\right.$. Ed.) Hauston: Gult Publishing.

9. Lindeman, F. C. (1926). The meaning of adult education. New York: New Republic.

10. Marton, F. (1978). Describing conceptions of the world around us. Reports from the institute of Education, no 66. Goteborg's University.

11. Marton, F. (1981) Phenomenography-describing conceptions of the world around us. Journal of Instructional Science, 10, 177-200.

12. Marton, F. (1986). Phenomenography - a research approach to investigating different understandings of reality. Journal of Thought, 21 (3), 28-49.

13. Marton, F., \& Booth, S. (1997). Learning and Awareness. Mahwah, New Jersey: Lawrence Erlbaum Associates.

14. Mezirow, J. (1996). Toward a learning theory of adult literacy. Adult Basic education 6(3), 115-126.

15. Patton, M. ((2002). Qualitative research \&evaluation methods $\left(3^{\text {rd }}\right.$ ed.), Thousand Oaks, CA: Sage.

16. Revans, R. (2011) ABC of Action Learning. England, Gower Publishing Limited.

17. The European Commission Green paper Entrepreneurship in Europe (2003). Data of access 16/05/2016 http://ec.europa.eu/invest-inresearch/pdf/download_en/entrepreneurship_europe.pdf 